\title{
Non-T Non-B CALLA Positive Adult Acute Lymphoblastic Leukemia
}

National Cancer Institute

\section{Source}

National Cancer Institute. Non-T Non-B CALLA Positive Adult Acute Lymphoblastic

Leukemia. NCI Thesaurus. Code C9144.

A non- $T$, non-B, acute lymphoblastic leukemia in which the lymphoblasts are positive for the common acute lymphoblastic leukemia antigen (CALLA) occurring in adults. 